crude assessments of glomerular function. Nor was there any significant difference between the results of the urine concentration tests performed in these groups. However, mean diastolic blood pressures were significantly increased in women who had had dysuria. This is consistent with other epidemiological evidence linking urinary tract infection with hypertension, ${ }^{1011}$ and it is of interest because any effect due to the inclusion of patients with impairment of renal function or bacteriuria has been excluded. Of the original 2,933 women $53(1.8 \%)$ recalled having dysuria before the age of 15 years. The same tests of renal function were carried out on 30 of these women. Again there were no significant differences from the control subjects in mean levels of plasma urea and creatinine, but there was evidence of a significant impairment of renal concentrating power. This suggests that persisting renal damage is more likely to be associated with urinary tract infections first acquired in childhood.

Even if these findings are generally reassuring they also illustrate the difficulty of detecting those patients in whom bacterial infection is either primarily or secondarily responsible for progressive renal destruction. The Cardiff workers have elsewhere concluded that screening for bacteriuria in adult non-pregnant women often fails to detect renal disease at an early and reversible stage. ${ }^{12}$ They have also found that antimicrobial treatment of asymptomatic bacteriuria in this

\section{Treatment of Rabies}

Until recently Britain has been free of rabies apart from occasional cases in dogs in quarantine; so doctors have had no impetus to get or keep themselves well informed about how to handle someone bitten by a suspected animal. However, with the continuing westward spread of rabies on the continent $^{1}$ (mainly fox rabies) and the recent cases in Britain of dogs developing rabies after release from quarantine all doctors ought now to be aware of the principles of treatment. Advice, antiserum, and vaccine are available from Dr. A. D. Macrae, Virus Reference Laboratory, Central Public Health Laboratory, Colindale, London N.W.9. The need for urgency in treatment has been clearly shown by a recent report ${ }^{2}$ from Vietnam of a soldier who was bitten on the finger and died of rabies 108 days later in spite of full treatment starting within about 36 hours. His death was attributed to the 36-hour delay in starting therapy.

The management of patients exposed to a risk of rabies is aimed at producing an immune state as quickly as possible so that the virus will not become established in a peripheral nerve along which it will travel to the central nervous system. Immunity is less effective after a nerve infection has been established. Rabies antiserum is administered to try to localize the infection to the wound and to establish immediate passive immunity. Vaccine is then given frequently and at a high dosage so as to establish the maximum active immunity in the shortest possible period. When antiserum is used it may reduce the effectiveness of the first few doses of vaccine;

1 Chronicle of the World Health Organization, 1970, 24, 47.

2 Dehner, L. P., Annals of Internal Medicine, 1970, 72, 375

3 Kaplan, M. M., Nature, 1969, 221, 421.

- Monthly Bulletin of the Ministry of Health and the Public Health Labor atory Service, 1967, 26, 201

5 World Health Organization. Technical Report Series. No. 321, p. 33

- Turner, G. S., British Medical Bulletin, 1969, 25, 136.

7 Crick, J., and Brown, F., Lancet, 1970, 1, 1106.

8 Crick, J., and Brown, F., Nature, 1969, 222, 92. context is unrewarding. ${ }^{13}$ The clinician will be grateful for such careful epidemiological work, which has better defined the risks associated with dysuria and with bacteriuria in non-pregnant adult women. These studies in adult women have highlighted the fact that it is among children that careful investigation, treatment, and follow-up are likely to produce the best results in terms of the preservation of functioning renal tissue. ${ }^{14} 15$

Steensberg, J., Bartels, E. D., Bay-Nielsen, H., Fanфe, E., and Hede, T British Medical fournal, 1969, 4, 390.

Waters, W. E., British fournal of Preventive and Social Medicine, 1969

Fry, J., Dillaine, J. B., Joiner, C. L., and Williams, J. D., Lancet, 1962, $1,1318$.

Mond, N. C., Percival, A., Williams, J. D., and Brumfitt, W., Lancet, 1965, 1, 514 .

Boyle, C. M., British Medical fournal, 1970, 2, 286.

Gallagher, D. J. A., Montgomerie, J. Z., and North, J. D. K., British Medical fournal, 1965, 1, 622

7 British Medical fournal, 1969, 4, 381

Guttmann, D., Proceedings of the 4th International Congress of Nephrology Stockholm, 1969, Abstracts 1, p. 382.

- Percival, A., Brumfitt, W., and de Louvois, J., Lancet, 1964, 2, 1027.

Miall, W. E., Kass, E. H., Ling, J., and Stuart, K. L., British Medical Fournal, 1962, 2, 497

"Bengtsson, U., Hogdahl, A-M., and Hood, B., Quarterly Fournal of Medicine, 1968, 37, 361.

12 Sussman, M., et al., British Medical fournal, 1969, 1, 799.

13 Asscher, A. W., et al., British Medical fournal, 1969, 1, 804.

14 Steele, R. E., Leadbetter, G. W., jun., and Crawford, J. D., New England fournal of Medicine, 1963, 269, 883.

is Smellie, J. M., and Normand, I. C. S., in Urinary Tract Infection, ed F. O'Grady, and $W$. Brumfitt, p. 123. London, Oxford University Press, 1963.

booster doses are therefore given after the end of the course.

Even in enzootic areas ${ }^{3}$ (which cover most of the world apart from islands like Britain, Australia, New Zealand, and Japan) it is often difficult to decide whether to treat a patient - the virus will not pass through intact skin, but even a slight injury may be sufficient to introduce infected animal saliva. In a rabies-free country where only imported or smuggled animals constitute a risk the difficulty is greater. However, anyone presenting with an animal bite (any warm-blooded animal) should be asked to identify the animal and whether it was imported even as long as a year before. If the animal was imported the police or the Divisional Veterinary Officer of the Ministry of Agriculture, Fisheries, and Food should be informed and will if necessary arrange for it to be kept under observation. If it survives 10 days the risk of rabies can be dismissed. Owners must be persuaded not to have pets destroyed within this period, since otherwise the diagnosis may not be confirmed or refuted.

If rabies is strongly suspected in the animal there must be no delay whatever in treatment. ${ }^{4}$ It should not await the results of laboratory diagnosis. The first step is to wash out the wound very thoroughly using a solution of $20 \%$ soap or an effective quaternary ammonium compound, ${ }^{5}$ if possible without surgical interference. Because of the shorter distance to the central nervous system, bites of the head and neck are most dangerous, followed by those on the upper limbs. In all such cases (and perhaps in all cases where there is strong suspicion) rabies antiserum (or preferably rabies gammaglobulin) should be given as early as possible and certainly within 24 hours. Part of the dose should be infiltrated around the wound and the remainder given intramuscularly. Precautions against serum sensitivity must be available, and it is wise first to make an intradermal test for sensitivity. Whether or not serum has been given, vaccine ${ }^{6}$ should be started immediately and 14 daily doses are usually given. If serum 
has been given booster doses of vaccine should be given 10 and about 20 days after the end of the course. ${ }^{5}$

If the suspected animal survives 10 days after the biting incident the treatment may be stopped. This is important if brain tissue vaccine is being given, since the fewer the doses the less risk of a paralytic reaction. Duck embryo vaccine ${ }^{6}$ does not cause such reactions and is therefore more often used, though it is not as immunogenic as is desirable and may cause other side effects. The best brain-tissue vaccines are more immunogenic. There is an urgent need for a safer and more immunogenic vaccine, and several are being developed in cell culture systems. ${ }^{6-8}$

Those particularly at risk (veterinarians and others working in quarantine kennels and carriers of imported animals) should be prophylactically immunized, preferably with a vaccine not made from brain tissue. ${ }^{4}$ They should be tested for antibody after the course and revaccinated until antibody can be demonstrated.

When seeking medical advice before going overseas for any reason but particularly on holiday members of the public should be made aware of the wide distribution of rabies and told to seek immediate medical advice if bitten by any warmblooded animal in an enzootic area. They should particularly beware of any unusually friendly or strangely behaving wild animal; these behavioural changes are common in rabies.

\section{The Specialty of Haematology}

In 1969 the Royal College of Physicians of London indicated that it wished to add clinical haematology to the list of specialties it sponsored. It considered that the clinical care of patients with blood diseases should be undertaken by a physician and not by a haematologist, whose work was esscntially in the laboratory. These views were reaffirmed in a further document issued in January this year, which added that future discussions about establishing the specialty of clinical haematology should take place with representatives of the Royal College of Physicians of Edinburgh and the Royal College of Physicians and Surgeons of Glasgow.

Close collaboration between haematologists and physicians in the management of patients with blood disorders has generally been the rule in Britain. In more and more hospitals the haematologist now fulfils the role envisaged in the new post proposed by the Royal College of Physicians. Much of the impetus for the College's action has come from a small group of physicians, generally members of academic departments of medicine, whose main interest is haematology, and who feel there is insufficient outlet for their clinical talents in the haematology departments of regional hospitals, presumably because such posts do not usually have direct access to beds. But even this is changing, and recent vacancies in haematology have demanded that the candidates not only provide a laboratory service but take clinical charge of patients with blood disorders. ${ }^{1}$

The views of the Royal College of Physicians were considered by the British Society for Haematology, and its report is printed at p. 788 of this week's B.M.F. The Society rejects the College's arguments and condemns the setting up of a new type of physician-haematologist who would take over the management of patients with blood disorders. While

1 British Medical fournal, 31 January 1970, advertisement page xxix.

- British Medical fournal, 1969, 1, 795. agreeing that a large hospital requires the services of several haematologists, these the Society suggests should specialize in one or more fields of haematology such as megaloblastic anaemias, leukemias, coagulation disorders, blood transfusion, etc. Care of the patient should continue to be the joint responsibility of physicians and haematologists, but all haematologists should have adequate outpatient facilities and access to a number of investigative beds.

These views of the British Society for Haematology were formulated only after all members (the vast majority of practising haematologists in Britain) had been approached and many had forwarded their views to the working party. The final document was approved unanimously at meetings of the British Society for Haematology held in Belfast and Cambridge in 1969 and 1970, respectively. These views are essentially similar to those advocated in these columns a year ago. ${ }^{2}$

The response of the Royal College of Pathologists to these problems has been muted. Apparently it does not distinguish between the fields of activity of its members, most of whom are histopathologists. Examinations in the four disciplines of pathology are moulded in the same pattern, and this in turn has determined a similar training programme. Attempts to vary the requirements for Membership of the College in haematology so as to introduce a greater element of clinical medicine-so essential if the College is to train clinical haematologists-have met with resistance. Agreement by haematologists and physicians on a common but flexible training programme embracing both laboratory and clinical aspects of the discipline appears to be essential. Clinical haematology is a worth-while career in itself, and should not be regarded as being one of a number of possible interests for a general physician. Neither is the viewpoint that suitable qualifications for clinical haematologists are the M.R.C.P. followed by the M.R.C.Path. likely to win much support from young men wishing to enter this field.

\section{Immunity and Human Malignant Melanoma}

The practical potentialities of tumour immunology in the management of human cancer are just beginning to emerge. Despite conclusive evidence from numerous studies of the immunological control of experimental cancers, there have so far been no convincing reports that progress of human tumours has been arrested or delayed by artificial immunization procedures. This week's report by the clinical and experimental tumour immunology team at the Chester Beatty Research Institute (page 752) is no exception to this, but it advances our understanding an appreciable step further.

In an earlier communication ${ }^{1}$ this team established the existence of tumour-specific cytotoxic autoantibodies for the first time in any human cancer. The tumour studied was malignant melanoma, and the effective antibody activity was found to be specific for the individual patient. Most patients with localized disease were found to have the antitumour antibodies, though these were not present when the disease was generalized. Antibody disappeared in individual patients as the disease progressed. However, it was not possible to say whether the tumours spread because the immune response

${ }^{1}$ Lewis, M. G., et al., British Medical fournal, 1969, 3, 547. 